\title{
Fly on the wall: Evolution of Attachment Devices in Lower Diptera
}

Katrin Friedemann \& Katharina Schneeberg

Entomology Group, Institut für Spezielle Zoologie und Evolutionsbiologie mit Phyletischem Museum,

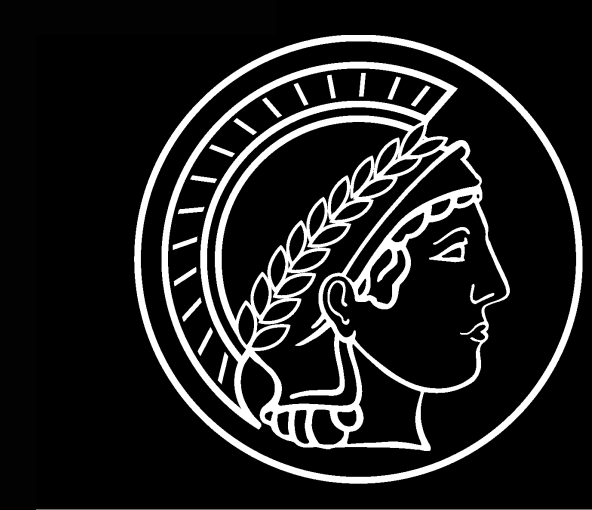

Friedrich-Schiller-Universität Jena. Email: katrinfriedemann@gmx.de

\section{Introduction}

Diptera are an extremely successful group of insects occurring in all zoogeographical regions. The remarkable diversification is accompanied by the evolution of different kinds of attachment structures. This is linked with the excellent flying abilities and the necessity to move efficiently on a very broad variety of substrates, including numerous different plant surfaces, rotting plant and animal materials, feces, and the integument of vertebrate hosts.

\section{Results and Discussion}

We investigated 32 species of Diptera and 10 outgroups. Both main types of attachment devices occur, hairy and smooth, but the former much more frequently. The different kinds of structures for attachment are: Arolium, a membranous median lobe of the pretarsus and autapomorphy of Tipulomorpha. It is filled with a gland producing an adhesive fluid.

Pulvilli, which are paired hairy lobes ventral to the claws. They are a groundplan feature of $\mathrm{Cu}$ licomorpha + (Bibionomorpha + Brachycera). The morphology of the adhesive hairs of the pads differs considerably between the groups.

Empodium, which is a median process between the pulvilli. A well-developed pad-like empodium with its ventral surface covered with tenent hairs is arguably a groundplan feature of Diptera. In the "higher" Brachycera there is a trend towards reduction of the empodial pad. It is reduced to a spine in some those groups.

\section{References}

Friedemann, K., Schneeberg, K., Beutel, R.G. (under review) Fly on the wall - Attachment Structures in Lower Diptera.

Wiegmann, B. M., Trautwein, M. D., Winkler, I. S., Barr, N. B., Kim, J.-W., Lambkin, C., Bertone, M. A. et al. (2011) Episodic radiations in the fly tree of life. PNAS, 108, 5690-5695. 